\title{
Human patient simulation to improve the attitude of the nursing students
}

\author{
Tuti Nuraini ${ }^{* 1}$, Efy Afifah ${ }^{1}$, Nur Agustini ${ }^{2}$, Hening Pujasari ${ }^{1}$, Masfuri ${ }^{3}$, Ariesta Milanti ${ }^{4}$ \\ ${ }^{1}$ Fundamentals of Nursing Department, Faculty of Nursing, University of Indonesia, Kampus UI Depok, Indonesia \\ ${ }^{2}$ Pediatric Nursing Department, Faculty of Nursing, University of Indonesia, Kampus UI Depok, Indonesia \\ ${ }^{3}$ Medical Surgical Nursing Department, Faculty of Nursing, University of Indonesia, Kampus UI Depok, Indonesia \\ ${ }^{4}$ Maternity Nursing Department, Faculty of Nursing, University of Indonesia, Kampus UI Depok, Indonesia
}

Received: August 28, 2014

DOI: $10.5430 /$ jnep.v5n4p52
Accepted: January 13, $2015 \quad$ Online Published: January 22, 2015

URL: http://dx.doi.org/10.5430/jnep.v5n4p52

\begin{abstract}
Attitude is an essential attribute of a nurse. Nursing education has an important role to shape the attitude of the nursing students, as a foundation of their attitude as nurses. The aim of this study was to evaluate the effect of the human patient simulation learning method on the attitude of the nursing students. Quasi-experimental, two group pre/post-test design was used. A total of 95 nursing students of the second year were given intervention and 37 students from another institution were assigned as control group. Second year students were selected as they were about to have clinical practice at the hospital. After the human patient simulation the attitude score statistically significantly increased in the intervention group $(p<.01)$. The attitude score in the intervention group rose by 18.7 points (scale $37-185$ ) and decreased by 8.2 point in the control group. The findings showed that the human patient simulation improved the attitude of the nursing students before having the actual learning experience with the patients at the hospital. Clinical learning environment in Indonesia is generally far from ideal to shape good attitude of the nursing students. Thus, human patient simulation is recommended to prepare the nursing students prior to clinical internship.
\end{abstract}

Key Words: Attitude, Nursing students, Role-play patient simulation, Learning method

\section{Introduction}

Attitude is an essential attribute of a nurse. The paradigm of the patient-centered nursing care requires nurses to see the patient as a unified whole. ${ }^{[1]}$ Attitude is the key to care for patient as a whole unique individual. A good attitude is also needed to build the caring relationship with the patients and to promote patient safety. It is the goal of the nursing practice to meet the needs of the patients in a holistic view within a caring interpersonal relationship. ${ }^{[2]}$

Nursing education has an important role to shape the attitude of the nursing students, as a foundation of their attitude as nurses. Thus, it is necessary to develop the learning methods to foster the attitude of the students to be able to provide a holistic nursing care. ${ }^{[1]}$ Patient simulation is an active teaching/learning strategy that is close to actual clinical experience and is recommended as a method to teach patient-centered nursing care. ${ }^{[3]}$

Prior studies corroborate the beneficial effects of patient simulation. Patient simulation may improve selfconfidence, ${ }^{[4]}$ clinical performance, ${ }^{[5]}$ problem solving skill, ${ }^{[6]}$ and teamwork competencies of the students. ${ }^{[7]}$ Students are also required to use and integrate their cognitive, affective and psychomotor skills in a simulation practice. ${ }^{[1]}$ In addition, through simulation practices students can improve their self-awareness and realize consequences of every action taken. ${ }^{[8]}$ Simulated learning at a hospital-like laboratory encourages students to use their critical thinking to

\footnotetext{
*Correspondence: Tuti Nuraini; Email: tutinfik@gmail.com; Address: Faculty of Nursing, University of Indonesia, Kampus UI Depok, Jawa Barat, Indonesia.
} 
anticipate and address clinical problems without harming any actual patients. Therefore, patient simulation mainly aims to enhance patient safety. ${ }^{[9]}$ It may both reduce the risk of clinical error and build the culture of patient safety. ${ }^{[6]}$

The students perceived the simulation in the preclinical studies as a positive learning experience. ${ }^{[10]}$ Learning environment of a simulated practice is designed for students and teachers to work together aiming at meeting the learning goals. ${ }^{[10,11]}$ Patient simulation practice encourages more kinesthetic learning that promotes a change in the attitude of the students. ${ }^{[12]}$

In Indonesia, educating future nurses with good attitude is a double challenge. In spite of the high demand of the society, the ever-increasing complexity of the health problems in Indonesia makes it very important for nurses to develop their competence as well as their attitude. ${ }^{[13]}$ However, most of the nursing education institutions in Indonesia are still lacking of methods, resources and standard to promote good nursing attitude. The previous study mentioned that there was no basic mannequin available to support simulation practice at the laboratory of the nursing schools, let alone high fidelity simulation. ${ }^{[14]}$ These institutions also did not have sufficient human patient simulation to facilitate skills, knowledge and attitude acquisition. Moreover, clinical fieldwork was also limited due to the increased number of nursing school with minimum hospital affiliation.

High fidelity human patient simulation showed promising results in clinical learning. ${ }^{[7,10]}$ However, it is hardly afforded by most of the nursing schools in a developing country such as Indonesia. Moreover, despite its highest technology, high fidelity human patient simulation still lacks a key element of the human being contact. ${ }^{[15]}$ Within this limited resource situation, using role-play human patient simulation among nursing student may serve as a feasible strategy.

One of the nursing schools in this study is the oldest and leading nursing higher degree institution in Indonesia. We have been contributing in the development of the national curriculum and teaching/learning strategy to be implemented throughout the country. In spite of the growing evidence of the benefits of the human patient simulation learning method, the effectiveness of this method had yet to be proven in Indonesia. Therefore it was necessary to assess the human patient simulation method in our context.

\section{Methods}

This research aimed to evaluate the human patient simulation in the laboratory on the nursing students' perception and attitude. This study was a quantitative study using quasi-experimental, pretest-posttest design with a comparison group. Comparison group was used to strengthen the research method, which is quasi-experimental. Ethical approval was obtained prior to the commencement of the

Published by Sciedu Press study. The simulation model was designed based on the Indonesian national nursing curriculum so that it could be incorporated into the national curriculum development in the future. Each core competence of the nursing curriculum was translated into the human patient simulation manual. The simulation involved teacher, student, learning process, simulation design characteristics and outcomes as its five key components. $^{[16]}$

The intervention group was a convenience sample of $95 \mathrm{sec}-$ ond year nursing students of a university in Depok, West Java, Indonesia. Meanwhile, the control group consisted of 37 nursing students of a university in Ciputat, South Jakarta, Indonesia. The characteristics of the students were having no previous clinical experience and generally feeling anxious, afraid and lacking of self-confidence.

The development of the human patient simulation learning method in this study underwent three main stages: preparation, model implementation and evaluation. The human patient simulation was initiated with the preparation of the student manual and scenarios of each adult nursing competences. Every simulation scenario was focused on a specific target and aimed to facilitate students to achieve the learning objectives. ${ }^{[16]}$ The learning objectives covered the clinical practice skills (i.e. wound care, oxygen therapy, chest physiotherapy, etc.), communication and interpersonal skills, time management for medication, and safety principles in nursing care. Furthermore, the scenarios were elaborated to be doable scenes in the role-play settings. Actors were then selected and trained to enact each scenario. Afterwards, with the assistance of the university theatre team, the human patient simulation was performed and recorded in a video. The simulation process was evaluated from the video recording and was refined accordingly. The video served as a reflective learning strategy for the students to meet the learning goals.

Meanwhile, pretest was conducted in order to measure the perception and attitude of the students prior to patient simulation. Pretest was consisted of two sets of instruments. The first one asked the students' perception on the learning process, the benefits of learning nursing science in life and the benefits of learning nursing science for the future. The second tool measured the attitude of the students. It measured the confidence of the students in providing professional nursing care.

The research team made and piloted both instruments. The instruments were developed based on previous study by $\mathrm{Pu}-$ jasari. ${ }^{[17]}$ The validity and reliability tests were conducted on 40 fourth year nursing students of the same university. The reliability test of the perception and attitude instrument yielded Cronbach $\alpha$ of 0.936 and 0.943 , respectively. Whereas, the validity of the perception instrument lied between 0.455 and 0.833 . On the other hand, the validity of the attitude instrument ranged from 0.321 to 0.815 . The range 
of total score of the students' perception was 15-105, while the attitude was 37-185. The average score of the perception was 1-7 and the attitude was 1-5.

The designed content of the human patient simulation was subsequently implemented within two weeks. A realistic hospital-like laboratory was set up to provide a supporting environment for the simulation learning. ${ }^{[17]}$

The last phase of the program was the evaluation phase. The first posttest was done to evaluate the effectiveness of the simulation practice. The students enrolled in clinical internship for five weeks after the first posttest. The second posttest was carried out afterwards to identify the students' ability to apply the competence they supposedly attained in the simulation and other learning processes at the academic setting. All data was then analyzed using statistical software.

\section{Results}

The data was normally distributed, thus paired T-test was used to analyze the data. The result showed an increased score of students' perception from $6.18 \pm 0.71$ to $6.21 \pm 0.72$, after having the human patient simulation practice. However, this result was not statistically significant. On the other hand, the students' attitude was statistically significantly increased from $3.39 \pm 0.54$ to $3.65 \pm 0.57(p=.001)$.

Table 1 summarizes the statistical test results of the perception and attitude of the students before and after the roleplay patient simulation. There was no significant difference on students' perception in the intervention and control group. However, the result showed a significant difference on the attitude of the intervention group after the intervention $(p=.000)$. Whereas, the control group showed no statistically significant difference on the attitude $(p=.094)$.

Table 1: The scores of the nursing students' perception and attitude of the intervention and control group before and after having human patient simulation

\begin{tabular}{|c|c|c|c|c|c|c|c|c|}
\hline \multirow{2}{*}{ No } & \multirow{2}{*}{ Variables } & & \multirow{2}{*}{$\mathbf{N}$} & \multicolumn{2}{|l|}{ Mean \pm SD } & \multirow{2}{*}{ Mean Diff. (95\%CI) } & \multirow{2}{*}{$t$} & \multirow{2}{*}{$\boldsymbol{P}$} \\
\hline & & & & Before & After & & & \\
\hline \multirow{2}{*}{1} & \multirow{2}{*}{ Perception } & Intervention & 95 & $86.96 \pm 21.33$ & $89.46 \pm 19.3$ & $-2.5(-8.11 ; 3.10)$ & -0.887 & .377 \\
\hline & & Control & 37 & $79.65 \pm 32.93$ & $87.5 \pm 19.3$ & $-7.86(-21.74 ; 6.01)$ & -1.15 & .258 \\
\hline \multirow{2}{*}{2} & \multirow{2}{*}{ Attitude } & Intervention & 95 & $123.9 \pm 19.54$ & $142 \pm 18.7$ & $-18.7(-23.63 ;-12.71)$ & -6.6 & $.000 *$ \\
\hline & & Control & 37 & $151 \pm 18.24$ & $143 \pm 17.84$ & $8.2(-1.48 ; 17.89)$ & 1.724 & .094 \\
\hline
\end{tabular}

*significant at $(p<.01)$

The scores of the components of the attitude of the nursing students are depicted in Figure 1. All the components increased in score after the role-play patient simulation. The highest improvement was shown on the administration of medication.

Table 2 showed that the score of the students' attitude when giving medication had the highest increase in mean difference. The attitude on giving medication increased by 0.815 in mean difference. It was even higher compared with the increase of the total attitude score. Table 2 also showed the significant increase of the total attitude score $(p=.000)$. The mean of the total attitude score significantly increased from $3.4 \pm 0.54$ to $3.93 \pm 0.53(p=.000)$. The mean values of each component of the attitude were also significantly higher after the patient simulation. The statistical test yielded $p$ value of .000 of the nine components of the attitude.

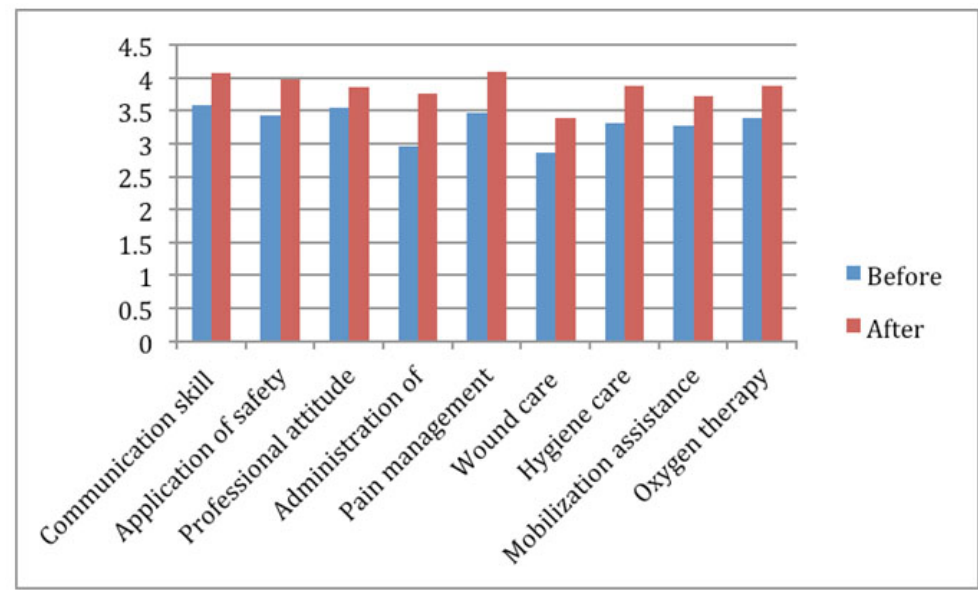

Figure 1: The scores of nursing students' attitudes before and after having role-play patient simulation 
Table 2: The scores of the nursing students' attitudes before and after having human patient

\begin{tabular}{|c|c|c|c|c|c|c|}
\hline \multirow{2}{*}{ No } & \multirow{2}{*}{ Attitude (scale 1-5) } & \multicolumn{2}{|l|}{ Mean \pm SD } & \multirow{2}{*}{ Mean Diff (95\%CI) } & \multirow{2}{*}{$T$} & \multirow{2}{*}{$\boldsymbol{P}$} \\
\hline & & Before & After & & & \\
\hline 1 & Communication skill & $3.59 \pm 0.58$ & $4.08 \pm 0.61$ & $-0.489(-0.658 ;-0.321)$ & -5.782 & $.000^{*}$ \\
\hline 2 & Application of safety principles & $3.43 \pm 0.61$ & $3.98 \pm 0.54$ & $-0.550(-0.710 ;-0.390)$ & -6.842 & $.000^{*}$ \\
\hline 3 & Professional attitude & $3.55 \pm 0.54$ & $3.86 \pm 0.54$ & $-0.308(-0.451 ; 0.164)$ & -4.261 & $.000^{*}$ \\
\hline 4 & Administration of medication & $2.95 \pm 0.75$ & $3.76 \pm 0.57$ & $-0.815(-1.007 ;-0.623)$ & -8.436 & $.000^{*}$ \\
\hline 5 & Pain management & $3.46 \pm 0.91$ & $4.09 \pm 0.76$ & $-0.632(-0.877 ;-0.386)$ & -5.116 & $.000 *$ \\
\hline 6 & Wound care & $2.87 \pm 0.68$ & $3.39 \pm 0.56$ & $-0.519(-0.710 ;-0.329)$ & -5.414 & $.000 *$ \\
\hline 7 & Hygiene care & $3.32 \pm 0.74$ & $3.88 \pm 0.62$ & $-0.563(-0.751 ;-0.375)$ & -5.945 & $.000 *$ \\
\hline 8 & Mobilization assistance & $3.28 \pm 0.67$ & $3.72 \pm 0.66$ & $-0.437(-0.629 ; 0.245)$ & -4.518 & $.000^{*}$ \\
\hline 9 & Oxygen therapy & $3.38 \pm 0.66$ & $3.87 \pm 0.59$ & $-0.493(-0.657 ;-0.328)$ & -5.940 & $.000^{*}$ \\
\hline \multicolumn{2}{|c|}{ Total attitude score } & $3.4 \pm 0.54$ & $3.93 \pm 0.53$ & $-0.529(-0.677 ;-0.381)$ & -7.089 & $.000 *$ \\
\hline
\end{tabular}

*significant at $p<.01$

\section{Discussion}

Human patient simulation learning method appears to be an effective laboratory-based learning method. It is beneficial for both students and teachers/instructors. ${ }^{[10,19]}$ Learning clinical competences through human simulation is both efficient and effective without compromising the safety of the real patients. ${ }^{[6,9]}$ Students are not necessarily afraid of harming the patients. The tension of the laboratory instructors is not as high as in teaching the junior students with inadequate clinical skills at the hospital. Moreover, students can have more practice on their clinical approach and skills at a hospital-like set up prior to the hands-on clinical practice. The designed scenarios of the human patient simulation practice also encourage the critical thinking and problem solving ability of the students.

The result of this study showed no significant increase of the perception of the nursing students after having human patient simulation at the laboratory. Prior study done also concluded similar results on the perception of the students after having patient simulation on intravenous access laboratory practice. ${ }^{[5]}$ This study explored the students' perception with regards to the patient simulation learning as well as general perception on nursing such as the how the nursing science might be useful in daily life and also in their future. The nursing students' perception was high already on the test commenced before the simulation: the mean was 6.18 out of 7 scale. The post-test showed an increased mean value of 6.21 , which, however, did not statistically significantly change. The high score on perception showed that the students perceived studying nursing science and also learning through human patient simulation as interesting, important and rewarding. The intervention group who consisted of the second year nursing students were more likely to have positive views on studying nursing science as they have adapted to the teaching-learning process in nursing school.

Recent study results showed the effectiveness of the method

Published by Sciedu Press of simulated patients in the laboratory to improve the attitude of nursing students. Before the intervention, there was a significant difference between the attitude control group and intervention group. Attitude in the intervention group was lower than the control group for the intervention group learning rate is lower than the control group. However, after one month of practice in the hospital, attitude of the control group decreased, while the attitude of the intervention group increased. Therefore, after a month of practice, they had the same attitude scores, with higher levels of learning in the control group. Clinical learning environment in Indonesia is generally far from ideal to shape good attitude of the nursing students. Many factors cause the clinical learning environment less conducive to the formation of nursing students' attitude. These factors are lack of role models, lack of mentor and perceptorship as well as oversized number of nursing students. Thus, human patient simulation is recommended to prepare the nursing students prior to clinical internship.

Human patient simulation was shown to have a positive impact on the students' attitude in this study. Most elements of the attitude - comprised of communication, applying safety principles, confidence on administering medication, pain management, wound care, personal hygiene, oxygen therapy, and assisting mobilization - significantly increased after the implementation of the patient simulation. Previous research results supported these positive findings on the students' confidence, skills, communication and attitude. ${ }^{[5,20,21]}$ Other research result also suggested that learning with simulated patients is a possible solution to improve the attitude of the health care professionals. ${ }^{[22]}$ Learning to deal with role-played patients with affection might help the student to develop their positive attitude towards patients. The learning environment was conditioned to resemble the real patient in a clinical situation. Therefore, the students were demanded to practice the best approach on their simulated patients, more than if they only had to deal with partial 
or complete human mannequin.

Bambini et al. underlined the attitude as the combination of the knowledge and skills in caring for patients. ${ }^{[20]}$ Thus, attitude constitutes of clinical judgment and decisionmaking, as well as professional behavior. ${ }^{[20]}$ The professional element in this study consisted of some sub-elements. These sub-elements were professional attire and appearance, smile, indiscrimination, responsibility and accountability, participation in the ward activities, clinical case discussion, collaboration, and nursing process performance. Nevertheless, in spite of its effectiveness to improve the students' attitude, it takes real situations in a longer time frame to foster the professional attributes of the nurses.

Human patient simulation allows the students to practice their critical thinking in delivering nursing care. Simulation is a vital learning method in nursing since it creates a situation in which the students can learn to build the relationship with the patients. ${ }^{[23]}$ Simulation does not necessarily compromised the patient safety and in other way, the students' safety as well. ${ }^{[9,19]}$ However, learning by using simulated patient requires adequate preparation and considerable effort from the teachers and educational institutions. Clinical scenarios and supporting equipment and facilities must be sufficiently organized. However, many sources for patient simulation are also available online, making it easier for preparing the clinical simulation scenario. ${ }^{[18]}$

Human simulation may require a certain amount of budget and tedious preparation for supporting facilities, creating clinical scenarios, ${ }^{[4,9]}$ making it recommended only as an addition to the laboratory learning with the mannequin. However, it may be less costly compared to the high fidelity human patient simulation, especially by using the available resources. ${ }^{[16]}$ Its reasonable economic value, nevertheless, does not compromise the effectiveness of the role-play simulation to achieve the learning goals. ${ }^{[11]}$

The present study found that the professional attitude, including the cooperation between the health care providers, could only significantly increase after the clinical hands-on practice at the hospital. This finding is consistent with the study result of Garbee. ${ }^{[7]}$ Effective teamwork and interprofessional communication is an important factor of the quality patient care as well as patient safety. Thus, learning this professional attitude using interdisciplinary patient simula- tion is also important.

A qualitative study done by a team from Rachel House Foundation and World Health Organization revealed that nursing students were found to be reluctant and unmotivated to enter nursing school. ${ }^{[24]}$ They mostly take nursing school, as it is relatively easy to get a job as a nurse. However, being in touch with patients as well as having clinical and laboratory practice, being moved by the lecturer or nurse instructor might increase the interest of the nursing students. Therefore, human simulation practice is a good way to nurture the professional value of the nursing students.

There were some limitations of this study, however, such as minimum size of control group. There was also limitation related to control group characteristics since the participants in the control group were not of the same year of study.

\section{Conclusions and recommendations}

Human patient simulation may improve the general attitude of the nursing students. This laboratory practice is beneficial to familiarize the students with the clinical situation prior to clinical practice at the hospital. It allows students to have more opportunities of practicing their critical thinking, basic nursing skills, communication and teamwork, according to the learning goals. In order to meet such goals, Human patient simulation takes considerable efforts on preparing the scenarios, actors, facilities and set ups. The study results suggested the human patient simulation as a safe yet an effective learning approach for students since their early year in nursing school. Human patient simulation is recommended to prepare the nursing students prior to clinical internship. Human patient simulation should be incorporated into the standard of nursing learning resource. Nevertheless, real interaction with the patients in the real clinical settings is necessary as none can substitute real experiences.

\section{Acknowledgements}

This study was funded by Directorate of Research and Community Service. University of Indonesia.

\section{Conflicts of Interest Disclosure}

The authors declare that there is no conflict of interest statement.

\section{References}

[1] Cordeau, M. A. Teaching holistic nursing using clinical simulation. A pedagogical essay. Journal of Nursing Education and Practice. 2013; 3(4): 40-50. http://dx.doi.org/10.5430/jnep.v3n4 $\mathrm{p} 40$

[2] American Nurses Association. Scope and standards of practice. Sil- ver Spring: American Nurses Association. 2006; 23

[3] Barrere, C. Teaching future holistic nurses: integrating holism into an undergraduate nursing curriculum. In Holistic Nursing: a handbook for practice. B Dossey \& L Keegan, eds. Boston: Jones and Bartlett. 2009; 709-717.

[4] Sleeper, J.A. \& Thompson, C. The use of high fidelity simulation to enhance nursing students' therapeutic communication skills. Inter- 
national Journal of Nursing Education Scholarship. 2008; 5(1): 42. PMid:19120033 http://dx.doi.org/10.2202/1548-923X.15 55

[5] Mahardika, Z. P. The effect of combined simulated patient and manikin for the achievement intravenous cannulation skills. (Unpublished bachelor's thesis). Gadjah Mada University, Yogyakarta, Indonesia. 2012

[6] Larew, C. \& Lessans, S. Innovations in clinical simulation: Application of Benner's theory in an interactive patients care simulation. Nursing Education Perspectives. 2006; 27: 16-21. PMid:16613127

[7] Garbee, D.D., Paige, J.T., Bonanno, L.S., Rusnak, V.V., Barrier, K.M. Effectiveness of teamwork and communication education using an interprofessional high- fidelity human patient simulation critical care code. Journal of Nursing Education and Practice. 2013; 3(3): 1-12.

[8] Nelson, D. L. \& Blenkin, C. The power of online role-play simulations: technology in nursing education. International Journal of Nursing Education Scholarship. 2007; 4(1): 1263-1277. PMid:17402925 http://dx.doi.org/10.2202/1548-923X.12 63

[9] Sanford, P.G. Simulation in nursing education: a review of the research. The qualitative report. Qualitative Report. 2010; 15(4): 1006-11.

[10] Flo, J., Flaathen, E. K., \& Fagerström, L. Simulation as a learning method in nursing education - A case study of students' learning experiences during use of computer-driven patient simulators in preclinical studies. Journal of Nursing Education and Practice. 2013; 3(8): 138-148. http://dx.doi.org/10.5430/jnep.v3n8p138

[11] Beddingfield, S., Davis, B.W., Gilmore, Melanie, L.J. The effect of high-fidelity simulation on examination performance. Teaching and Learning in Nursing. 2011; 6(2): 46-9. http://dx.doi.org/10.1016/j.teln.2010.10.001

[12] Strand, I., Naden, D. \& Slettebo, A. Students learning in a skills laboratory. Nursing Science. 2009; 29(3): 18-22.

[13] Shields, L. \& Hartati, L.E. Nursing and health care in Indonesia. J. Adv. Nurs. Journal of Advanced Nursing. 2003; 44: 209-216. PMid:14521687 http://dx.doi.org/10.1046/j.13652648.2003.02785.x

[14] Masfuri, Herawati, T., Pramita, Miko, Aulawi, K., Kristianawati, et al. Studi kebijakan: OSCE Nasional. Jakarta: Health Professional Education Project, Dirjen Dikti Kemendikbud. 2012.
[15] Rose, S., Courey T., Ball, M., Bowler, C. \& Thompson, Z. Bringing simulation to life through a therapeutic encounter: a pedagogical approach used for associate degree nursing students. Teaching and Learning in Nursing. 2012; 7(1): 2-5. http://doi:10.1016/j. teln.2011.09.00

[16] Irwin, R.E. The diffusion of human patient simulation into an associate degree in nursing curriculum 1 . Teaching and Learning in Nursing. 2011; 6(4): 153-158. http://dx.doi.org/10.1016/j .teln.2011.02.004

[17] Pujasari, H. Nursing students' and nurse educators' perceptions and attitudes towards bioscience in an Indonesian bachelor of nursing program. Unpublished thesis: The University of Melbourne. 2007.

[18] Hyland, D., Weeks, B. H., Carmel, T., Ficorelli, M.V. Bringing simulation to life. Teaching and Learning in Nursing. 2012; 7(3): 108112. http://dx.doi.org/10.1016/j.teln.2012.01.002

[19] Brewer, E.P. Successful techniques for using human patient simulation in nursing education. Journal of Nursing Scholarship. 2011; 43(3): 311-317. PMid:21884377 Available from: http://www.nc bi.nlm.nih.gov/pubmed/21884377

[20] Bambini, D., Washburn, J., Perkins, R. Outcomes of clinical simulation for novice nursing students: communication, confidence, clinical judgment. Nursing Education Perspectives. 2009; 30(2): 79-82. PMid:19476069 Available from: http://www.ncbi.nlm.nih.g ov/pubmed/19476069

[21] Greenberg, R., Loyd, G., \& Wesley G. Integrated simulation experiences to enhance clinical education. Medical Education. 2002; 36: 1109-1110. PMid:12406301 http://dx.doi.org/10.1046/j.1 365-2923.2002.136131.x

[22] Kneebone, R.L., Scott, W., Darzi, A., Horrocks, M. Simulation and clinical practice: strengthening the relationship. Medical Education. 2004; 38(10): 1095-1102, http://doi/10.1111/j.1365-2929. 2004.01959.x

[23] Rose S, Courey T, Ball M, Bowler C. Bringing simulation to life through a therapeutic encounter: a pedagogical approach used for associate degree nursing students 1 . Teaching and Learning in Nursing. 2012; 7(1): 2-5. http://dx.doi.org/10.1016/j.teln.20 11.09 .003

[24] Rachel House Foundation \& World Health Organization. Potensi pengembangan pendidikan keperawatan paliatif bagi siswa dan praktisi keperawatan di Indonesia. Paper presented at the Stakeholder Discussion. Indonesia, Jakarta, March 26, 2014. 